Kinger. HCA Healthcare Journal of Medicine (2021) 2:2

https://doi.org/10.36518/2689-0216.1226

\title{
Essay
}

\section{After Code Blue}

Author affiliations are listed at the end of this article.

Komal Kinger, $\mathrm{MD}^{1}$

\section{Abstract}

\section{Description}

Starting intern year comes with its own challenges and learning opportunities, especially in a pandemic. In this paper I reflect on one such situation. The code and passing of a particular patient earlier this year taught me many lessons and it has impacted the type of physician I aspire to be.

\section{Keywords}

graduate medical education; internship and residency; death; grief; cardiopulmonary resuscitation; CPR; cardiac arrest; code blue; psychological adaptation; coping; medical humanities

It's a sight I know I will never forget. There she was, my patient who was ready to be discharged that day, lying between the bathroom and her bed in a pool of blood. Her eyes were wide open, with the life already gone from her. The next few minutes were, at the same time, painfully slow and fast. I remember running to call a code blue and a frantic flurry of movements that followed. The patient was lifted to the bed and compressions were started. Flashes of green and blue scrubs came running in and out, a crash cart screeching against the tiles behind them. Voices filled the room, medications were prepped, EKG leads were placed on the patient's chest. One, two, three, thump, thump, crack as the medical students performed compressions while I attempted to palpate a femoral pulse. To an outsider the room would have seemed like organized chaos. The senior resident was at the head of the bed, compressors were switching and counting out loud, nurses were calling out times and pulse checks. Amongst all the noise the occasional Clear! was heard as everyone stepped away from the bed and her chest jumped with each shock. The patient began vomiting from the compressions and breaths as her ribs continved to crack. Sadly, twenty-one minutes later a time of death was pronounced.
As gruesome as this code was, it is not the only reason that this code will be forever etched in my memory. It's the aftermath of the code that surprised me the most. This was not the first code that I was involved in-three months into intern year I had seen several codes, and surprisingly none of them had affected me the way this code had. And I can't really put a finger on why this one affected me so much, but it did help me realize that this is the one part of residency and medicine that can't be taught. Because although there are multiple resources available with instructions on how to handle a code, with algorithms that precisely outline methods and simulations to put them in practice, it's the aftermath of the code that I realized was the hardest part for me. Unfortunately, it was something that I had to experience for myself.

I remember thinking on pre-rounds that morning that the patient, who had been diagnosed with a terminal illness, would finally be able to go home and see her loved ones, rather than interacting with masked strangers in the hospital during a pandemic. I remember chatting with the patient, informing her of her discharge plans, and the last thing that she said to me was "alright baby girl." She was one of the first patients I felt that I had truly gotten

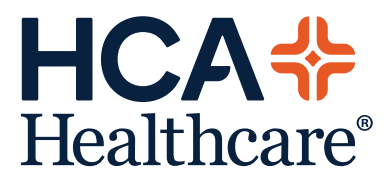

www.hcahealthcarejournal.com

(c) 2021 HCA Physician Services, Inc. d/b/a Emerald Medical Education

\author{
HCA Healthcare \\ Journal of Medicine
}


to know during the first few months of intern year, having admitted her twice before. Her voice was still ringing in my ears after she was pronounced deceased. All I could think about as I walked out of that room was 'don't cry, don't do it now, hold it together.' Despite what had just happened, we had seven other patients to take care of and were still receiving admissions and I owed it to my patients to give them $100 \%$ of what I had.

When that work day finally ended and I went home, drained, exhausted, and overwhelmed, with specks of blood on my scrubs, all my emotions caught up with me. I finally felt that I was able to grieve for my patient. I felt sad and disappointed in myself, not only for having lost a patient but also for letting it affect me so deeply. It seemed as if everyone had accepted the loss after the debriefing and were able to process it much more quickly than I had, and here I was crying as if I had lost everything. When I called my family that night for support, they reminded me of a quote that crying is not a sign of weakness, but rather a sign of strength. They told me that expressing your emotions so outwardly takes courage. There is no rulebook on how long it takes one to grieve or to recover. What matters is what you take away from it.

I am grateful for what this code taught me. It taught me that expressing my emotions made me stronger and helped me come to terms with a difficult situation. It also showed me how incredibly fortunate I am to have such a strong network of family, friends, and colleagues in my residency program and that I am as strong as the people I surround myself with. I am thankful for my senior resident who stepped up to the plate. He not only ran a smooth code in a difficult situation, but debriefed with us as a team and went out of his way to check in on each member of the team, from the medical students to the intern. I am thankful for my attending, who guided us during our debriefing and reminded us why we had been inspired to be in medicine in the first place, even though we felt far from inspired at that moment. I am thankful to the attending physician from another team who heard about our code and stopped by to check in on us, and even brought snacks to help cheer us up and make sure we had eaten. I am thankful to my co-interns who heard about the code and texted me at the end of the night to offer a sympathetic ear. These little things made all the difference in helping me process the code. With their support it took a few days to 'refill my emotional tank' as I called it. I started re-exploring activities that I loved, including writing. It took a terrible situation to help me discover what the worst of the aftermath could feel like and how to ensure I had the tools in my back pocket to be able to process it.

When I pass by the room in which the code had occurred, I sometimes find myself thinking back to the moment when we walked into that room unknowingly with smiles and left with our heads hung and hearts heavy. What I learned is that the response during the aftermath of the code is as equally important as the response to the code. And although there is no tried and trusted algorithm on how to process one, it is a critically important part of becoming a physician.

\section{Conflicts of Interest}

The author declares she has no conflicts of interest.

The author is an employee of Memorial Health University Medical Center, a hospital affiliated with the journal's publisher.

This research was supported (in whole or in part) by HCA Healthcare and/or an

HCA Healthcare affiliated entity. The views expressed in this publication represent those of the author(s) and do not necessarily represent the official views of HCA Healthcare or any of its affiliated entities.

\section{Author Affiliation}

1. Memorial Health University Medical Center, Savannah, GA 